\title{
COL4A1-related familial vascular leukoencephalopathy
}

INSERM

\section{Source}

INSERM. (1999). Orphanet: an online rare disease and orphan drug data base. COLAA1related familial vascular leukoencephalopathy. ORPHA:36383

COL4A1-related familial vascular leukoencephalopathy is a rare, genetic, neurological disease characterized by the presence of fragile small-vessel intracerebral vasculature in various members of a single family, manifesting, clinically, with single or recurrent hemorrhagic and/or ischemic stroke and, frequently, ocular and renal involvement. Neuroimaging reveals diffuse, periventricular leukoencephalopathy associated with dilated perivascular spaces, lacunar infarction and microhemorrhages. 